\title{
ESTIMATION OF RADIOMETRIC CALIBRATION COEFFICIENTS OF EGYPTSAT-1 SENSOR
}

\author{
A. H. Nasr, B. M. El Leithy, H. S. Badr \\ National Authority for Remote Sensing and Space Sciences, 23 Joseph Broz Tito St., El-Nozha El-Gedida, \\ P.O. Box: 1564 Alf-Mascan, Cairo, Egypt - (aymanasr, belal, hs)@ narss.sci.eg
}

KEY WORDS: Egyptsat-1 Sensor, Calibration Coefficients, At-Sensor Spectral Radiance, Spot-4 Satellite, Multispectral Bands, Linear Regression.

\begin{abstract}
:
Sensors usually must be calibrated as part of a measurement system. Calibration may include the procedure of correcting the transfer of the sensor, using the reference measurements, in such a way that a specific input-output relation can be guaranteed with a certain accuracy and under certain conditions. It is necessary to perform a calibration to relate the output signal precisely to the physical input signal (e.g., the output Digital Numbers (DNs) to the absolute units of at-sensor spectral radiance). Generic calibration data associated with Egyptsat-1 sensor are not provided by the manufacturer. Therefore, this study was conducted to estimate Egyptsat-1 sensor specific calibration data and tabulates the necessary constants for its different multispectral bands. We focused our attention on the relative calibration between Egyptsat-1 and Spot-4 sensors for their great spectral similarity. The key idea is to use concurrent correlation of signals received at both sensors in the same day (i.e., sensors are observing the same phenomenon). Calibration formula constructed from Spot-4 sensor is used to derive the calibration coefficients for Egyptsat-1. A brief overview of the radiometric calibration coefficients retrieval procedures is presented. A reasonable estimate of the overall calibration coefficient is obtained. They have been used to calibrate reflectances of Egyptsat-1 sensor. Further updates to evaluate and improve the retrieved calibration data are being investigated.
\end{abstract}

\section{INTRODUCTION}

Deriving absolute reflectance for space borne platforms is of interest to all geoscientists as it offers an opportunity to know the composition and spectral property of materials. In order to record and standardize the specific sensors measurements, the sensors' output measurement is converted into voltages that are then read by the analog-to-digital (A/D) converter. For example, the signals received at the satellite (measured radiance) are provided to the user in form of DNs. These DN values do not quantitatively correspond to the physical units such as radiance, reflectance or temperature. Thus, for estimation of quantitative spectral surface characteristics we need to convert the DN first to absolute units of at-sensor spectral radiance using the calibration data and consequently to target reflectance.

Calibration traditionally refers to the process of correcting systematic errors in sensor readings. The term has also often been used in reference to the procedure by which the raw outputs of sensors are mapped to standardized units, i.e. absolute radiometric calibration puts the data on a standard scale and makes it compatible and comparable with the data acquired from different sensors (Gurol et al., 2008). Moreover, re-calibration is usually required in order to ensure proper operation of a measurement device, as ageing and other factors impact sensors and measurement hardware over time (Bychkovskiy et al., 2003). A significant amount of calibration research work has been done (Biggar, et al., 1991; Van Der Horn \& Huijsing, 1997; Mendenhall \& Parker, 1999; Tahnk \& Coakley, 2001; Whitehouse \& Culler, 2002; Markham et al., 2004; Chander et al., 2007; Vickery \& Beckley, 2009; HaiLiang, G., 2010; and O'Dell et al., 2011) to name a few.
Radiometric calibration is a prerequisite for creating highquality image data. It is necessary to provide individual calibration data for every manufactured sensor. Since generic calibration data associated with Egyptsat-1 are not known, in addition to the huge amount of its acquired data, this study was conducted to estimate the specific radiometric calibration coefficients of Egyptsat-1 sensor and tabulate the necessary constants for its Multispectral bands. These conversions provide a basis for standardized comparison of data in a single scene or between images acquired on different dates or by different sensors (Chander et al., 2009).

\section{CONVERSION FROM DIGITAL NUMBER TO AT-SENSOR RADIANCE}

An image comprises of a series of spectral bands, the pixels of which each have a DN. In a raw unprocessed image, pixel DN is a linearly transformed representation of at-sensor radiance for a discrete resolved area of the Earth's surface (Lillesand and Kiefer, 1999). Image spectrometric studies and atmospheric correction operations, however, need at-sensor radiance. Radiometric calibration of the sensors involves converting the raw DN transmitted from the satellite to units of absolute spectral radiance. The following equation is used to perform the conversion:

$$
L=\left(\frac{L_{\max }-L_{\min }}{D N_{\max }}\right) \times D N+L_{\text {min }}
$$

As pixel DN is a simple linear transformation of radiance, the gain and offset of this linear transformation can be used to 
calculate radiance $\mathrm{L}$ (measured in $\left[\mathrm{W} /\left(\mathrm{m}^{2} \mathrm{sr} \mu \mathrm{m}\right)\right]$ ). These gain and offset values are unique for each spectral band acquired by a particular sensor. These values change over the life span of a sensor according to its sensitivity changes, so their most recent values should be used.

\section{DATA ACQUISITION}

While at present, there is no way to know the radiometric calibration coefficients of Egyptsat-1, besides the ceased communication between Egyptsat-1 and the ground control station in Cairo, we focused our attention on the relative calibration between Egyptsat-1 and Spot-4 sensors for their great spectral similarity. Egyptsat-1 is the first Egyptian earth observation satellite which was successfully put in orbit on 17/04/2007. It is a microsatellite technology built in cooperation with the Ukraine. Egyptsat-1 sensor captures both multi-spectral and panchromatic images (Nasr and Helmy, 2009). The characteristics of its data are as follows:

- The spatial resolutions of the Multi-spectral and the panchromatic bands are 7.8 meter.

- The spatial resolution of the Mid-Infrared band is 39.5 meter.

Spot-4 is one of the French satellite series that have been launched from Kourou, French Guyana in 24/03/1998 with a repetitive cycle of 26 days. It has two HRVIR instruments scanning total swath of $120 \mathrm{~km}$ field of view. Panchromatic (Black and white) resolution $10 \mathrm{~m}$, colour 3 spectral bands resolution $20 \mathrm{~m}$ and MIR band resolution $20 \mathrm{~m}$. Egyptsat-1 and SPOT-4 spectral resolutions are summarized in Table 1.

\begin{tabular}{|c|c|c|c|}
\hline Bands & Description & Misrsat-1 & SPOT-4 \\
\hline band 1 & Green & $0.51-0.59$ & $0.51-0.59$ \\
\hline band 2 & Red & $0.61-0.68$ & $0.61-0.68$ \\
\hline band 3 & Near Infrared & $0.80-0.89$ & $0.79-0.89$ \\
\hline band 4 & Panchromatic & $0.50-0.89$ & $0.61-0.68$ \\
\hline band 5 & Mid Infrared & $1.10-1.70$ & $1.18-1.75$ \\
\hline
\end{tabular}

Table 1: The Spectral Resolutions $(\mu \mathrm{m})$ of the Egyptsat-1 and The SPOT-4 Data

\section{METHODOLOGY}

\subsection{Calibration Coefficients Estimation Procedure}

Our proposed calibration method derives relative calibration relationships between Egyptsat-1 response and an external calibrated source, Spot-4 response. The key idea is to use correlation of image DN's received at the two sensors in the same day. The post-launch gain and offset for each detector of the first three bands of Egyptsat-1 sensor are individually calculated by a linear regression of the corresponding three detector responses of the Spot-4 sensor. The slope of the regression represented the gain, while the intercept represented the offset. Procedures for calculating the specific radiometric calibration coefficients of Egyptsat-1 sensor are performed in the following steps:
1- A pair of values collected at exactly the same day by two sensors represents a potential data point of a calibration function between these sensors. Two equivalent images from Egyptsat-1 and SPOT-4 for the same area (Port Saied, Egypt) acquired on the same day $(14 / 6 / 2010)$ at clear weather conditions were selected, as shown in figure 1 .

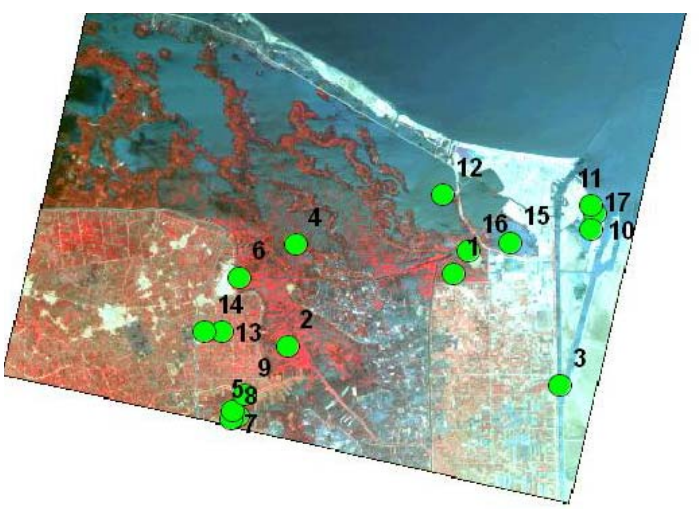

(a) Egyptsat-1 image

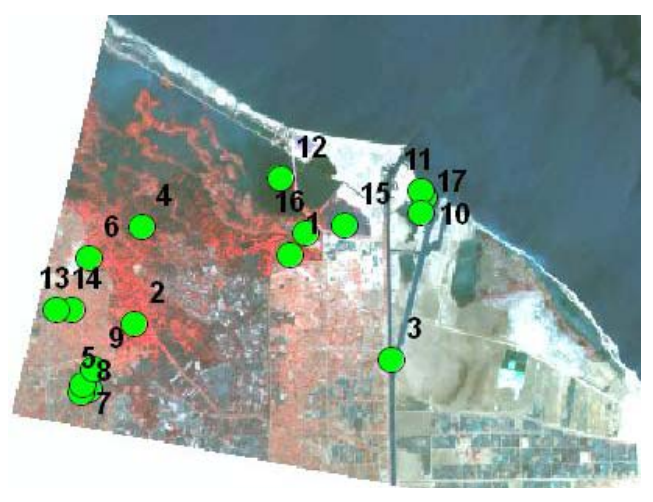

(b) SPOT-4 image

Figure 1. Equivalent images of Port Saied area, Egypt

2- We identified the maximum possible number of identical features in the two images and extracted the digital numbers at these selected features of the first three bands (B1, B2, and B3), as shown in table 2 . 
International Archives of the Photogrammetry, Remote Sensing and Spatial Information Sciences, Volume XXXIX-B1, 2012 XXII ISPRS Congress, 25 August - 01 September 2012, Melbourne, Australia

\begin{tabular}{|c|c|c|c|c|c|c|c|c|}
\hline \multirow{2}{*}{$\#$} & \multirow{2}{*}{ Lat. } & \multirow{2}{*}{ Lon. } & \multicolumn{2}{|c|}{ DN (Egyptsat- $)$} & \multicolumn{3}{|c|}{ DN (SPOT-4) } \\
\cline { 5 - 9 } & & & B1 & B2 & B3 & B1 & B2 & B3 \\
\hline 1 & 311125 & 321308 & 43 & 38 & 123 & 52 & 31 & 141 \\
\hline 2 & 310816 & 320455 & 43 & 36 & 132 & 56 & 32 & 158 \\
\hline 3 & 310642 & 321827 & 55 & 54 & 61 & 69 & 43 & 35 \\
\hline 4 & 311241 & 320518 & 41 & 37 & 93 & 57 & 36 & 98 \\
\hline 5 & 310518 & 320529 & 82 & 37 & 135 & 55 & 32 & 170 \\
\hline 6 & 311114 & 320231 & 41 & 36 & 130 & 60 & 38 & 132 \\
\hline 7 & 310511 & 320210 & 48 & 52 & 76 & 71 & 53 & 69 \\
\hline 8 & 310530 & 320211 & 42 & 41 & 72 & 58 & 41 & 72 \\
\hline 9 & 310612 & 320248 & 42 & 38 & 132 & 59 & 39 & 143 \\
\hline 10 & 311406 & 322008 & 57 & 78 & 49 & 92 & 90 & 40 \\
\hline 11 & 311424 & 321956 & 50 & 56 & 46 & 71 & 58 & 37 \\
\hline 12 & 311452 & 321232 & 70 & 79 & 102 & 124 & 104 & 117 \\
\hline 13 & 310854 & 320137 & 49 & 52 & 76 & 73 & 55 & 71 \\
\hline 14 & 310852 & 320045 & 46 & 45 & 58 & 64 & 44 & 46 \\
\hline 15 & 311249 & 321557 & 51 & 48 & 54 & 66 & 40 & 35 \\
\hline 16 & 311226 & 321352 & 66 & 74 & 94 & 103 & 80 & 93 \\
\hline 17 & 311322 & 321957 & 53 & 79 & 51 & 80 & 87 & 37 \\
\hline
\end{tabular}

Table 2: Digital numbers for Egyptsat-1 and SPOT-4 at identical selected features

3- To manually calculate the correct calibration coefficients, we have assumed a linear calibration function. The equation of a line relating the two sensor's output has been determined. We used the standard equation of a line, $\mathrm{Y}=\mathrm{a} \mathrm{X}+\mathrm{b}$, to calculate the calibration coefficients. Therefore, the formula that governs the relation between the digital counts of SPOT-4 and Egyptsat-1 for each equivalent band is indicated by $\mathrm{A}$ and $\mathrm{B}$ constants in the following equation:

$$
D N_{\text {SPOT }}=A \cdot D N_{\text {Egyptsat }}+B
$$

The following Figures 2, 3, and 4 illustrate Scatter plots of pairs of data values (DN's) taken by Egyptsat-1sensor readings (Xaxis) and Spot-4 readings (Y-axis) for the first three different bands. A relationship between them could be established by fitting a line through the points (linear correlation). Table 3 represents the calculated constants for each band.

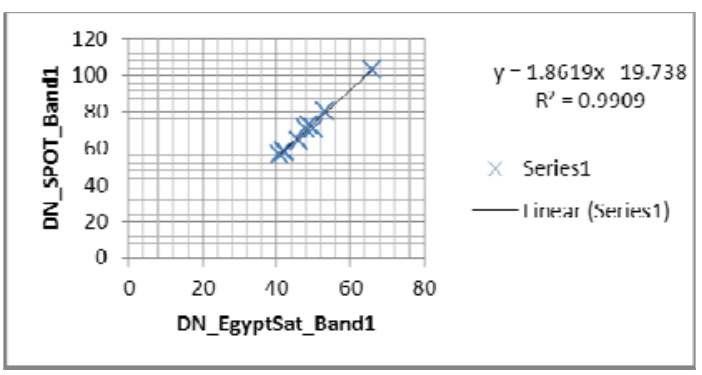

Figure 2. Scatter plot of SPOT-4 and Egyptsat-1 DN's for the first band

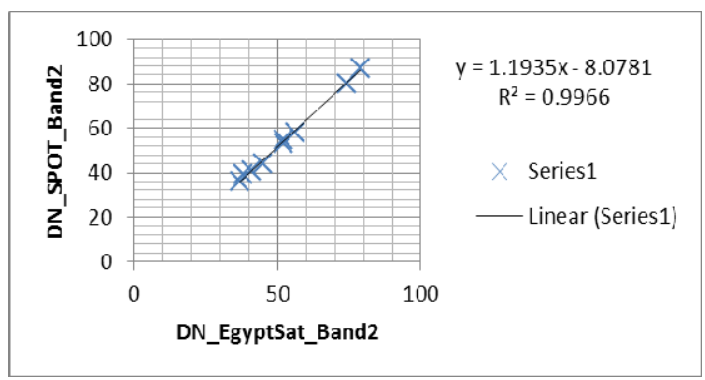

Figure 3. Scatter plot of SPOT-4 and Egyptsat-1 DN's for the second band

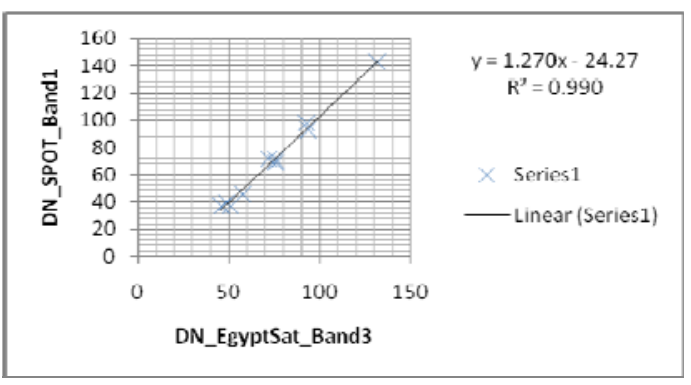

Figure 4. Scatter plot of SPOT-4 and Egyptsat-1 DN's for the third band

\begin{tabular}{|c|c|c|c|}
\hline & Band1 & Band2 & Band3 \\
\hline A & 1.8619 & 1.1935 & 1.2701 \\
\hline B & -19.738 & -8.0781 & -24.277 \\
\hline
\end{tabular}

Table 3: Constants calculated for the relation between SPOT-4 and Egyptsat-1 DN's for each band

4- Finally, the radiometric calibration coefficient for Egyptsat- 1 could be deduced in more mathematical details using the following expressions:

Given, $\quad L=$ Gain $_{\text {SPOT }} D N_{\text {SPOT }}+$ Offset $_{\text {SPOT }}$

From equation (2),

$$
\begin{aligned}
& L=\operatorname{Gain}_{\text {SPOT }}\left(A \cdot D N_{\text {Egyptsat }}+B\right)+\text { Offset }_{\text {SPOT }} \\
& L=A \cdot \operatorname{Gain}_{S P O T} D N_{\text {Egyptsat }}+B \cdot \text { Gain }_{S P O T}+\text { Offset }_{S P O T}
\end{aligned}
$$

The previous equation yields:

$$
\begin{aligned}
& \text { Gain }_{\text {Egyptsat }}=A \cdot \text { Gain }_{\text {SPOT }} \\
& \text { Offest }_{\text {Egyptsat }}=B \cdot \text { Gain }_{\text {SPOT }}+\text { Offset }_{\text {SPOT }}
\end{aligned}
$$

Knowing the recent gain and offset of the Spot-4 sensor, Table 4 lists the estimated calibration coefficients (Gain and Offset) for Egyptsat-1 for the three different bands. 


\begin{tabular}{|c|c|c|c|}
\hline Egyptsat-1 & Band1 & Band2 & Band3 \\
\hline Gain $\left[\mathrm{W} /\left(\mathrm{m}^{2} \mathrm{sr} \mu \mathrm{m}\right)\right]$ & 3.032477 & 1.462634 & 1.458202 \\
\hline Offset $\left[\mathrm{W} /\left(\mathrm{m}^{2} \mathrm{sr} \mu \mathrm{m}\right)\right]$ & -32.1473 & -9.89971 & -27.8724 \\
\hline
\end{tabular}

Table 4: The estimated radiometric calibration coefficients for Egyptsat-1

Atmospheric correction is the process of removing/ compensating for atmospheric distortions that influence the signal at the top of the atmosphere. ATCOR model of ERDAS IMAGINE software was used to correct for atmospheric effects associated with the Egyptsat-1 image using the estimated calibration coefficients. This model accounts for the effects of atmospheric water vapour and influence of adjacent ground measurements. Figure 5 shows the image before and after atmospheric correction.

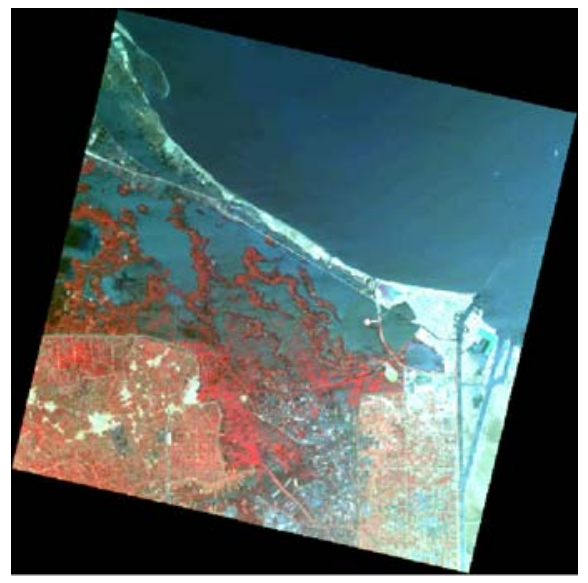

a) Before atmospheric correction

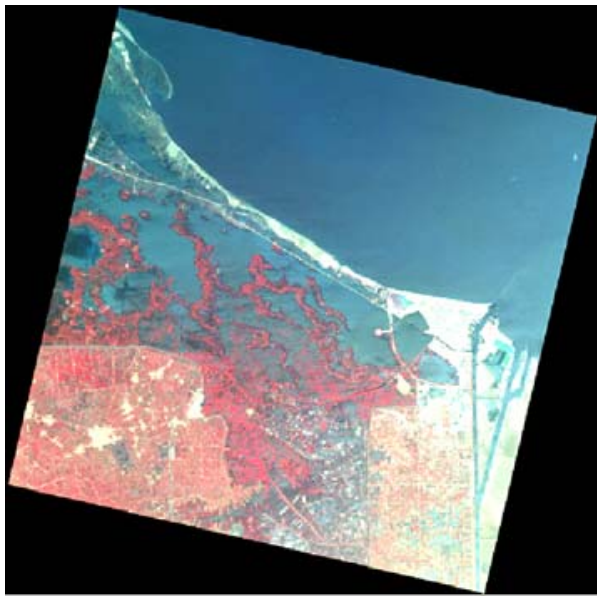

b) After atmospheric correction

Figure 5. Egyptsat-1 image before and after atmospheric correction

From the above results, one can see that we could estimate the radiometric calibration coefficients of the Egyptsat-1 sensor and atmospherically correct its data successfully as well.

\section{CONCLUSIONS}

In this paper we provide a brief overview of the radiometric calibration coefficients retrieval procedures for Egyptsar-1 sensor. The estimation of these coefficients has been done successfully, based on equivalent SPOT-4 data for their great spectral similarity. The study represents the equations and rescaling factors for converting Egyptsat-1calibrated DNs to physical units, such as at-sensor spectral radiance and tabulates the necessary constants for its three different bands. Studies are ongoing to evaluate the derived calibration coefficient. Further updates to improve the calibration are being investigated.

\section{REFERENCES}

Biggar, S. F., Dinguirard, M. C., and Gellman, G. I., 1991. Radiometric Calibration of SPOT 2 HRV-A comparison of three methods. SPIE, 1493, pp. 155-162.

Bychkovskiy, V., Megerian, S., Estrin, D. and Potkonjak, M., 2003. A Collaborative Approach to In-Place Sensor Calibration.

Chander, G., Angal, A., Choi, T., Meyer, D. J., Xiong, X., and Teillet, P. M., 2007. Cross calibration of the Terra MODIS, Landsat-7 ETM+ and EO-1 ALI sensors using near simultaneous surface observation over Railroad Valley Playa, Nevada test site. In J. J. Butler \& J. Xiong (Eds.), Proceedings of SPIE Conference 6677 on Earth Observing Systems XII, SPIE, 6677. San Diego, CA, pp. 1-12.

Chander, G., Markham, B. L. and Helder, D. L., 2009. Summary of current radiometric calibration coefficients for Landsat MSS, TM, ETM+, and EO-1 ALI sensors. Remote Sensing of Environment, 113, pp. 893-903.

HaiLiang, G., XingFa, G., Tao, Y., Hui, G., JiaGuo, LI. and XiaoYing, LI., 2010. HJ-1A HSI on-orbit radiometric calibration and validation research. SCIENCE CHINA, Technological Sciences. 53(11), pp. 3119-3128.

Lillesand, T.M. and Kiefer, R.W., 1999. Remote Sensing and Image Interpretation, John Wiley \& Sons, Inc, 9(10), pp. 592597.

Markham, B. L., Chander, G., Morfitt, R., Hollaren, D., Mendenhall, J. F., and Ong, L., 2004. Radiometric processing and calibration of EO-1 Advanced Land Imager data. Proceedings of PECORA 16 "Global Priorities in Land Remote Sensing” South Dakota: Sioux Falls.

Mendenhall, J. A. and Parker, A. C., 1999. Spectral calibration of the EO-1 Advanced Land Imager. Proceedings of SPIE Conference 3750 on Earth Observing Systems IV, SPIE, 3750, pp. 109-116.

Nasr, A. H. and Helmy, A. K., 2009. Integration of Misrsat-1 and SPOT-2 Data for Quantitative Change Detection Applications. ICGST-GVIP Journal, 9(5), pp. 53-59.

O'Dell, C.W., Day, J.O., Pollock, R., Bruegge, C.J., O'Brien, D.M., Castano, R., Tkatcheva, I., Miller, C.E., and Crisp, D., 2011. Preflight Radiometric Calibration of the Orbiting 
International Archives of the Photogrammetry, Remote Sensing and Spatial Information Sciences, Volume XXXIX-B1, 2012

XXII ISPRS Congress, 25 August - 01 September 2012, Melbourne, Australia

Carbon Observatory. IEEE Transactions on Geoscience and Remote Sensing. 49(6), pp. 2438 - 2447.

Tahnk, W. R. and Coakley, J. A., 2001. Improved calibration coefficients for NOAA-14 AVHRR visible and near-infrared channels. International Journal of Remote Sensing 22(7), pp. 1269-1283.

Van Der Horn, G. and Huijsing, J. H., 1997. Integrated Smart Sensor calibration. Analog Integrated Circuits and Signal Processing, 14, pp. 207-222.

Vickery, P. E. and Beckley, J. P., 2009. Calibration Coefficients for Sensor Based Measurements.

http://www.faqs.org/patents/app/20090055120

Whitehouse, K. and Culler, D., 2002. Calibration as parameter estimation in sensor networks. ACM International Workshop on Wireless Sensor Networks and Applications (WSNA'02), Atlanta, Georgia.

\section{ACKNOWLEDGEMENTS}

The authors are grateful to the National Authority for Remote Sensing and Space Sciences (NARSS) in Egypt for supporting this study. 